\title{
GESTÃO ESCOLAR DEMOCRÁTICA E ESTUDOS ORGANIZACIONAIS CRÍTICOS: CONVERGÊNCIAS TEÓRICAS
}

\author{
Cláudia Souza PASSADoR* \\ THALES SILVEIRA SALVETTI ${ }^{* *}$
}

\begin{abstract}
RESUMO: Este artigo trata da democratização da gestão escolar como componente imprescindível de uma educação de qualidade que vise à transformação social, abordando inicialmente os temas mais abrangentes de modo a desencadear a reflexão sobre o próprio conceito de gestão, numa perspectiva crítica, a partir de determinados quadros teóricos de referência nos assuntos em questão. Nessa tônica, demonstram-se as convergências teóricas entre as concepções de gestão escolar democrática e os Estudos Organizacionais Críticos apresentados, recomendando a ampliação de espaços de discussão entre teorias educacionais e organizacionais e também a consideração da proposta autogestionária como via democratizante.
\end{abstract}

Palavras-chave: Qualidade da educação. Gestão escolar democrática. Estudos Organizacionais Críticos. Autogestão.

\section{SCHOOL MANAGEMENT DEMOCRATIZATION AND CRITICAL ORGANIZATIONAL STUDIES: THEORETICAL CONVERGENCE}

ABSTRACT: This paper approaches school management democratization as a vital component of quality education that seeks social transformation. Initially, it discusses broader themes in order to generate reflection upon the very concept of management, in a critical perspective, through theoretical references in this field. It then demonstrates the theoretical convergence between the notions of democratic school management and the Critic Organizational Studies presented, recommending the broadening of the scope of discussion between educational and organizational theories. It also suggests considering the self-management proposal as a means for democratization.

Key words: Quality of education. Democratic school management. Critical organization studies. Self-management.

\footnotetext{
* Doutora em Educação e professora da Faculdade de Economia, Administração e Contabilidade de Ribeirão Preto, Universidade de São Paulo (USP). E-mail: cspassador@usp.br

** Mestrando em Administração de Organizações na Faculdade de Economia, Administração e Contabilidade de Ribeirão Preto, Universidade de São Paulo (USP). E-mail: tas.salvetti@bol.com.br
} 


\title{
Gestion SCOlaire démocratique et ÉTUdes
}

ORGANISATIONNELLES CRITIQUES: CONVERGENCES THÉORIQUES

\begin{abstract}
RÉSUMÉ: Cet article aborde la démocratisation de la gestion scolaire comme le composant indispensable d'un enseignement de qualité qui cherche à la transformation sociale. Tout d'abord, il s'approche largement des thèmes et ensuite les englobe afin d'aboutir à une réflexion sur le concept de gestion lui-même, dans une perspective critique, à partir de certaines références théoriques dans les sujets concernés. Dans ce chemin, il démontrent les convergences théoriques entre les conceptions de gestion scolaire démocratique et les Études Organisationnelles Critiques présentées, tout en suggérant l'élargissement d'espaces de discussion entre les théories scolaires et organisationnelles bien que la considération de la proposition autogestionnaire comme moyen de démocratisation.
\end{abstract}

Mots-clés: Qualité de l'enseignement. Gestion scolaire démocratique. Critiques Études Organisationnelles. Autogestion.

\section{Introdução}

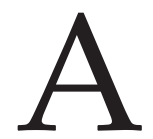

compreensão de que uma educação de qualidade é fundamental para o desenvolvimento do país alastrou-se nas últimas décadas a ponto de se tornar notória no Brasil, sendo raro encontrar alguém que hoje discorde dessa relevância. Também é de conhecimento comum que a escola, mesmo não se constituindo em elemento único da educação, é parte indispensável desta e tem um papel essencial na sociedade por meio do ensino formal. Contudo, se nos dias atuais a importância de um ensino de qualidade é praticamente inconteste para a sociedade e para o Estado (nas suas disposições constitucionais e legais), o mesmo não pode ser dito a respeito das acepções e implicações que essa ideia carrega.

Disserta-se neste artigo sobre a qualidade da educação escolar em seu aspecto administrativo, onde se defende para a escola e sua gestão uma perspectiva de transformação social apoiada em características democráticas, voltada para a emancipação dos sujeitos, no sentido de torná-los capazes de transcender suas realidades materiais e metafísicas, e orientada para o combate às desigualdades entre indivíduos. Essas questões foram levantadas de modo ordenado a fim de que, a partir dos assuntos de maior abrangência, os conceitos expostos desencadeassem os assuntos mais específicos e centrais aqui propostos, entre eles a concepção crítica do significado de administrar, tendo em vista principalmente o meio escolar.

Assim, a construção do texto que segue não esconde seu posicionamento ideológico perante o tema, acompanhando as noções de Demo (2008) de que o objeto de estudo das ciências sociais é histórico, contextual, portanto sua objetividade não é definitiva, nem estática, mas se dá em termos de perspectiva, visto que o sujeito pensante e o objeto (sociedade) estão interligados. Desse modo, sem relegar valores, 
interesses e posturas políticas inerentes, procura-se demonstrar a semelhança entre os conteúdos suscitados, quanto à gestão escolar democrática e os estudos organizacionais críticos, fundamentando a argumentação proposta com a devida objetividade científica ao tomar por base o seguinte quadro teórico de referência:

\section{Quadro 1}

\begin{tabular}{|c|l|l|}
\hline $\begin{array}{c}\text { Principais autores } \\
\text { citados }\end{array}$ & $\begin{array}{c}\text { Estudos em qualidade de ensino } \\
\text { e gestão escolar democrática }\end{array}$ & $\begin{array}{c}\text { Estudos Organizacionais } \\
\text { Críticos }\end{array}$ \\
\hline $\begin{array}{c}\text { Luiz Fernandes Dourado, Licínio } \\
\text { Ça, Vitor Henrique Paro e Demer- } \\
\text { val Saviani. }\end{array}$ & $\begin{array}{l}\text { Ana Paula Paes de Paula, } \\
\text { Fernando C. Prestes Motta, } \\
\text { Alberto Guerreiro Ramos e } \\
\text { Maurício Tragtenberg. }\end{array}$ \\
\hline $\begin{array}{c}\text { Principais obras e } \\
\text { autores consultados }\end{array}$ & $\begin{array}{l}\text { Miguel G. Arroyo (ARROYO, } \\
\text { 2010), Teise O. G. Garcia (GAR- } \\
\text { CIA, 2006), Acácia Z. Kuenzer } \\
\text { (KUENZER, 1985) e José M. R. } \\
\text { Pinto (PINTO, 1996) }\end{array}$ & $\begin{array}{l}\text { Miguel P. Caldas, Roberto } \\
\text { Fachin, Tânia Fischer, Cyn- } \\
\text { thia Hardy, Stewart R. Clegg } \\
\text { e Walter R. Nord (CALDAS } \\
\text { et. al. 2001), José Henrique de } \\
\text { Faria (FARIA, 2009), Maurí- } \\
\text { cio R. Serva de Oliveira (OLI- } \\
\text { VEIRA, 1996) }\end{array}$ \\
\hline \multicolumn{2}{|c|}{} \\
\hline
\end{tabular}

\section{A qualidade do ensino e a gestão escolar democrática}

A respeito da democratização do ensino brasileiro, Mendonça (2000, p. 80) lembra que o assunto não foi único e consensual ao longo do tempo, já que teve e tem, até hoje, significados distintos para muitas pessoas. Para alguns, seu entendimento resume-se ainda à universalização do acesso à escola e foi principalmente essa questão da expansão de matrículas, especificamente no ensino básico, a ter sido perseguida e implementada no Brasil nas últimas décadas, tanto por força de mobilizações sociais acerca do tema, quanto por exigência constitucional a partir de 1988. O Estado, nesse período, foi capaz de promover grande expansão no acesso da população à escola pública brasileira, ${ }^{1}$ mas esse crescimento não veio acompanhado de preocupação e cuidados, por parte dos governos, em relação à qualidade da educação, a qual é imprescindível à democratização da educação, no sentido de dirimir as diferenças de formação e de oportunidades dadas aos alunos advindas dessas distâncias qualitativas.

Ao se falar de qualidade em educação é vital que se faça aqui uma diferenciação: o conceito "tradicional" de qualidade de ensino a considera passível de medição 
por meio de testes que pontuem a quantidade de informações exibidas pelos alunos, de acordo com Paro (2007). Segundo este autor, essa concepção não apenas predomina nas estatísticas utilizadas pelos organismos governamentais, propagando-se de maneira majoritariamente superficial e acrítica por toda a mídia, como acaba por embasar muitos estudos acadêmicos sobre políticas públicas em educação. Nesse sentido, confunde-se a qualidade de ensino com as aprovações, ou notas obtidas pelos alunos, nas tradicionais disciplinas curriculares, como Português e Matemática, exaltando-se assim escores que representam a suposta "efetividade" da escola em transmitir uma maior quantidade desses conhecimentos específicos aos educandos. Essas informações curriculares não deixam de ser fundamentais. O que não se deve é tratar da qualidade de ensino, como um todo, pautando-se somente em termos quantitativos, pois assim não são levados em consideração os importantes fatores subjetivos da educação, como a assimilação de valores, gostos, posturas, crenças e aptidões, bem como aquilo que o autor considera ser um elemento mais relevante que buscar e auferir resultados: verificar e desenvolver os processos educativos.

A visão que baseia este artigo sobre a qualidade em educação e, inserida nesse universo, a qualidade de educação escolar, como dizem Dourado, Santos e Oliveira (2007), é de um conceito amplo, complexo e historicamente constituído, portanto em constante edificação. Os autores tratam de algumas questões consideradas fundamentais desse conceito que se aplicam ao ambiente escolar, bem como às condições objetivas e subjetivas para os aspectos pedagógicos, de avaliação e de administração escolar, que devem incluir um conjunto de qualidades como: a disposição de recursos não mínimos, mas suficientes para oferecer os insumos indispensáveis às múltiplas necessidades escolares, boas condições de trabalho, de materiais, de infraestrutura, de gestão, entre outros, capazes de proporcionar e induzir as escolas à concretização de seus objetivos pedagógicos, à realização de uma função social inclusiva e transformadora, à construção de sujeitos engajados técnica, pedagógica e politicamente.

Embora existam na Constituição Federal mais recente e na Lei de Diretrizes e Bases da Educação Nacional referências e princípios da gestão democrática e da qualidade do ensino público, essas disposições legais esbarram tanto na insuficiência em descrever e definir com maior precisão mecanismos que garantam ações administrativas educacionais efetivamente mais democráticas, explica Mendonça (2000), assim como num Estado cujas história e estrutura são marcadas por características oligárquicas e patrimonialistas, burocráticas e tecnicistas e, mais recentemente, neoliberais, conforme as abordagens complementares de Ramos (1983) e Paes de Paula (2005). Características estas que tiveram seus diferentes momentos mais marcantes na administração pública brasileira, mas que podem ser percebidas com nitidez até os dias atuais e demonstram formas de governo e gestão ainda muito distantes dos 
ideais republicanos e democráticos constitucionalmente previstos, principalmente no que se refere à descentralização do poder e à busca por igualdade social.

Entre os fatores essenciais à qualidade de ensino, conforme aponta Mendonça (2000), figura a gestão escolar democrática, que aparece pela necessidade de alteração das estruturas de poder na gestão dos sistemas de ensino público, incluindo, além das escolas, os departamentos, secretarias e outros órgãos educacionais, os quais não apenas são tutelados e regulamentados pelos sistemas políticos, como trazem consigo boa parte das características históricas anteriormente citadas desse Estado, sendo a gestão democrática uma provável resposta ao insucesso da escola pública nacional em democratizar e fornecer um ensino de qualidade, em que pese uma administração escolar voltada para a transformação social em detrimento de uma administração escolar marcada pela racionalidade capitalista excludente.

Paro (2001a) desenvolve essa lógica explicando que as escolas públicas brasileiras, de maneira geral, são reprodutoras da injustiça social, já que recolocam as pessoas nos lugares reservados por relações econômicas, formando-as para um mercado de trabalho com pequenas chances de mobilidade social. Disto decorre que, se é desejável uma escola transformadora que não alimente esse ciclo, é preciso transformar a própria escola e essa mudança passa pela necessidade de profundas alterações nos sistemas de autoridade e de distribuição de trabalho no interior da escola. O que se tem hoje é um sistema hierárquico que, em tese, concentra todo o poder nas mãos do diretor, gerando, porém, uma contradição: o diretor supostamente possui direito e autonomia para comandar, mas, de fato, por sua condição de responsável último pelo cumprimento legal, acaba por exercer muito mais esta função que a de gestor escolar, em suas atribuições administrativas e pedagógicas. Esse estado de falta de autonomia do diretor é um reflexo da situação de pouca autonomia da própria escola, e somente na medida em que se conseguir a participação de todos os setores envolvidos com a escola (professores, alunos, pais, funcionários e comunidade), atribuindo-lhes poder de decisão sobre os objetivos e o funcionamento desta, é que haverá condições para pressionar os escalões superiores, sendo esta a única forma crível a conquistar recursos satisfatórios e autonomia para a escola. Por essas razões, o anseio de um papel transformador passa pela democratização da gestão escolar.

Também acerca da concepção de gestão escolar democrática do ensino público, Mendonça (2000) separa cinco categorias essenciais distintas, mas intimamente relacionadas, expressando-as do seguinte modo:

1) A participação dos diferentes segmentos da comunidade escolar e, mesmo da comunidade externa, considerando-a o pano de fundo de todos os fatores que possam propiciar e materializar os processos da gestão democrática, na 
medida em que os interesses da população, portanto públicos, sobreponham-se a interesses particularistas, sendo este um tema em que teoria e legislação já avançaram bastante, embora a prática ainda demonstre a prevalência de diretores, professores e funcionários em relação aos pais e outros integrantes nos foros de participação;

2) A maneira como cada sistema realiza o provimento dos cargos de diretor, ${ }^{2}$ sendo mais tradicional o cargo de confiança por meio de nomeação, o qual é altamente criticável por abrir caminhos ao clientelismo e apadrinhamento político, além de sua volátil vinculação aos ciclos políticos. A adoção de concurso público como forma de provimento do cargo é um mecanismo alternativo que representa avanços à indicação, mas a qualificação, com critérios de impessoalidade, pré-requisitos de diplomação e medição por prova, não garante a competência do profissional, aproximando-o mais da figura do funcionário burocrático. A eleição de diretores pela comunidade escolar (sendo apenas os professores elegíveis ao cargo) é o processo que melhor materializa a luta contra o autoritarismo na administração da educação, de acordo com o autor. Há, por fim, o sistema misto de provimento, com pré-seleção de candidatos por meio de provas de conhecimento seguida de alguma forma participativa de escolha dos classificados;

3) A implantação e o funcionamento dos colegiados, os quais, apesar das dificuldades para se formarem e funcionarem relativas ao relacionamento entre os diferentes segmentos representantes da comunidade escolar, em especial com o diretor, são ainda um mecanismo essencial à promoção do despojamento da dominação de uma só pessoa, o que remete à quarta categoria;

4) A descentralização pedagógica, administrativa e financeira, a qual, defende Mendonça (op. cit.), não deve se restringir aos aspectos formais da gestão educacional, pois estes não se estendem às questões de processos participativos ou a alterações nas estruturas de poder dos sistemas de ensino, visto que as burocracias centrais e intermediárias expandem-se cada vez mais, justificando-se por meio da criação numerosa de projetos e exigências formais e assim prejudicando a autonomia escolar. As descentralizações também não devem significar completa desvinculação das responsabilidades do Estado com a escola e vice-versa, basta olhar para o exemplo da descentralização financeira que, devido à escassez de recursos, torna-se administração da escassez, em que a escola é instada a superar por si mesma suas dificuldades materiais - ideia esta compartilhada por Paro (2001a) -, funcionando como fator agravante de abandono e 
distanciamento do Estado por isentá-lo, em parte, desse ônus, e podendo ainda aumentar o fosso entre escolas de um mesmo sistema, visto que comunidades em melhor situação econômica naturalmente possibilitariam condições especiais às escolas de seus filhos, enquanto outras, em piores contextos, não conseguiriam o mesmo, aprofundando as desigualdades entre elas;

5) A autonomia escolar, na qual o projeto político pedagógico é apontado, quando sua elaboração é participativa, como uma das principais expressões coletivas da comunidade escolar na busca de sua identidade e, por conseguinte, da autonomia escolar. Contudo, Mendonça (2000, p. 417) completa o raciocínio constatando que:

[...] não há registros de que as administrações centrais tenham realizado adaptações radicais no sentido de considerar a escola como centro e razão de ser da existência de sua burocracia. Ao contrário, o que se pode verificar pela análise das normas fixadas pelos sistemas de ensino em relação à autonomia escolar é que os documentos são muito parcimoniosos no estabelecimento de mecanismos concretos que caracterizem a faculdade de a escola governar-se por si própria, mas profusos em estabelecer limites que verdadeiramente barram sua autonomia.

Para a concretude de um projeto de escola pública de qualidade, no caso da administração escolar, Paro (2007, p. 27) insiste que seus objetos de estudo devem considerar tanto a realização dos fins educativos quanto as mediações necessárias para concretizá-los, ou atividades-meio, e não somente as atividades de direção, tendo em vista a finalidade democrática intrínseca a empreendimentos realmente educacionais - finalidade esta que não se reduz ao "consumidor que tem direitos", mas se caracteriza pela participação ativa dos cidadãos na vida pública, tanto como "titulares de direitos" quanto como "criadores de novos direitos". Pode parecer óbvia a necessidade de adequação dos meios aos fins, afirma Paro (2001a), mas no ensino público essa evidência é permanentemente ignorada, tanto pela insistente sonegação de recursos materiais e financeiros em quantidades minimamente razoáveis para fazer frente às atividades inerentes à escola, quanto pelo uso de processos administrativos que negam imperativamente o objetivo de relações humanas livres de dominação, essencial a qualquer esforço realmente educativo. Articulada a essa medida, prossegue o autor, é também vital dotar a unidade escolar de autonomia administrativa e financeira em relação ao Estado, não se tratando de abandono por parte deste ao seu dever de financiar o ensino, mas de descentralização efetiva de todos os recursos que podem ser geridos pela escola, exigindo desta a prestação de contas direta e disponibilizando mecanismos que permitam, aos usuários, a fiscalização sobre a aplicação dos recursos disponíveis. De acordo com Paro (2001a), não é questão de defender uma pureza para a escola que a deixaria fora da realidade 
humana, mas de entendê-la como um meio de transformação que não renuncie a seu papel histórico de contribuir para a superação, pelos sujeitos, da alienação ${ }^{3}$ e ausência de criticidade prevalentes no processo capitalista de produção. Constatando o conservadorismo da teoria e da prática da administração escolar vigente, Paro (2001b) traz alguns pressupostos básicos de uma administração escolar de fato comprometida com a transformação social. O primeiro deles diz respeito à especificidade da administração escolar, assumindo seu papel revolucionário na medida em que consiga levar os sujeitos ao direito de se apropriarem do saber historicamente acumulado pela humanidade, desenvolvendo consciência crítica da realidade em que se encontram. $\mathrm{O}$ segundo se relaciona às racionalidades internas e externas à escola, em que pesem as determinações sobre a sua função perante a sociedade e seus objetivos próprios, que não podem ser neutros, a-históricos, mas direcionados a essa função. $O$ terceiro trata da participação coletiva, sem a qual suas atribuições e finalidades, aqui já discutidas, se tornariam educacionalmente inválidas. O quarto se refere à consideração das condições concretas para essas realizações, as quais incluiriam novos padrões de racionalização do trabalho e de coordenação dos esforços humanos coletivos, além de questões sobre os recursos suficientes, também anteriormente já levantadas.

Se faz sentido preocupar-se com a gestão das escolas, Paro (2001b, p. 18) alerta que é preciso considerar inicialmente o próprio conceito de administração, ou de gestão (tomados aqui como sinônimos), adotando assim uma concepção mais simples destas, como "utilização racional de recursos para a realização de determinados fins" - lembrando que, para a educação e o ensino, esses fins vinculam-se às funções sociais previamente citadas -, com o propósito de lhes atribuir um significado abrangente, menos associado às suas determinações históricas e sociais, em especial àquelas do modo de produção capitalista e de uma sociedade de classes. Sob essa ótica torna-se possível raciocinar os termos em que essa administração pode ser apurada para que esteja voltada à mudança social e a propósitos não autoritários.

Após expor aqui algumas concepções acerca da qualidade de ensino e da gestão escolar democrática, nota-se ao menos um juízo de valor comum, entre os autores, a esses conceitos: a perspectiva de transformação social. No campo teórico, a distinção crítica desses autores, ao enxergarem esse valor como possibilidade real, apesar do conjunto de estruturas objetivas e subjetivas capitalistas desfavoráveis, pode ser explicada por Saviani (2008), que parte do problema da marginalidade para classificar as outras teorias educacionais em dois grupos:

1) Teorias que pressupõem a educação como um mecanismo de inserção social, logo, de superação da marginalidade, porque veem esta como fator 
acidental da sociedade, uma distorção a ser corrigida. Nesse contexto a educação tem a função de reforçar os laços sociais, integrando e conformando os indivíduos ao corpo social e evitando sua desagregação. Desse ponto de vista a educação possui grande autonomia diante da sociedade, por ser muito mais determinante desta que o contrário. Assim sendo, por encarar a educação como independente e buscar compreendê-la a partir dela mesma, desconsiderando seus condicionantes objetivos (a estrutura socioeconômica em que estão inseridos os fenômenos educativos), Saviani (2008, p. 5) denomina este primeiro grupo de "teorias não críticas";

2) Teorias que concebem a sociedade como sendo marcada pela divisão de classes, cujos interesses opostos as mantêm em conflito. A marginalidade, nesse cenário, é vista como parte inerente à estrutura social que ocorre por apropriação desproporcional, pelos grupos dominantes, dos frutos da produção social. Consequentemente, parcela dessa sociedade é relegada à marginalidade. Nessa situação, essas teorias entendem a educação como subordinada à estrutura socioeconômica geradora de marginalidade e, portanto, reprodutora da marginalização e dominação. Por esse motivo, são denominadas pelo autor como "teorias crítico-reprodutivistas".

De fato, pontua Saviani (op. cit.), a escola na sociedade capitalista reproduz a exploração e a dominação, conservando um caráter segregador, de natureza seletiva, já que é determinada socialmente. Contudo, prossegue o autor, se não é possível descontextualizar a escola de seus condicionantes objetivos, também não é sensato pensá-la fatalmente aprisionada por essa estrutura socioeconômica. Desse modo, uma teoria crítica da educação que não seja reprodutivista só poderá ser construída a partir do interesse dos dominados.

Da inferência a respeito de uma teoria crítica da educação que não seja reprodutivista, surge uma questão proveniente da mesma encontrada em Saviani (2008), dotada de uma pequena modificação restritiva ao objeto de interesse (a escola), mas não de conteúdo (administração escolar), com o intuito de adequá-la ao tema central deste artigo: é possível uma teoria que capte criticamente a gestão escolar como um instrumento capaz de contribuir para a superação do problema da marginalidade?

Tendo em conta a sugestão de Paro sobre a relevância de pensar o próprio conceito de administração quando se trata do ambiente escolar e que, conforme proposto por Saviani, essa elaboração teórica deve ser permeada pela criticidade não reprodutivista, segue-se agora para o aprofundamento na questão de uma teoria crítica em administração. 


\section{Estudos Organizacionais Críticos}

O termo que dá título a esta segunda parte está vinculado ao artigo de Paes de Paula et al. (2010), assim como ao livro de Paes de Paula (2008), nos quais os Estudos Organizacionais Críticos (EOC) recebem atenção pelo pioneirismo, tradição nacional e base científica diferentes dos trabalhos estrangeiros dessa natureza. Da leitura desses trabalhos foram selecionadas algumas características aqui consideradas mais relevantes. Destaca-se, primeiramente, a origem dos EOC, que está ligada ao nome de dois principais autores, sendo eles: Alberto Guerreiro Ramos e Maurício Tragtenberg, cujas obras evidenciam-se pela base epistemológica considerada como humanista radical, por seu alinhamento com a fenomenologia e o existencialismo, que inspiraram Ramos, com o marxismo heterodoxo e o anarquismo, peculiares a Tragtenberg, e com a competência dialógica no questionamento radical de pressupostos científicos da Escola de Frankfurt. Em segundo lugar, cabe aqui uma breve explanação de Paes de Paula (2008, p. 111) sobre as significações que esse humanismo radical implica e que são compartilhadas por Ramos e Tragtenberg, sendo elas: a importância que atribuem ao sujeito, individual ou coletivo (classes), e à ação deste nas organizações, incorporando a criticidade e a desesperança de que os sujeitos possam se emancipar no contexto de corporações econômicas, mas sem descartar essa possibilidade de vida em outros formatos organizacionais, em que exemplos práticos de participacionismo e autogestão ${ }^{4}$ ajudam a vislumbrar um cenário compatível com a autonomia e a autoconsciência. ${ }^{5}$ Por fim, faz-se necessário suscitar o que é ser crítico para os EOC, o que foi feito por Davel e Alcadipani (2003), ao estabelecer três parâmetros fundamentais para apontar um estudo do campo da administração como sendo de natureza crítica, os quais serão aqui abordados somente nas dimensões que concernem ao tema deste artigo, conforme segue:

1) A adoção de uma visão desnaturalizada da administração, que assume a organização como construção social e histórica, denunciando aspectos de dominação, exploração, controle e exclusão na teoria e na prática administrativa, em contraposição ao processo de naturalização utilizado pelas teorias administrativas tradicionais, que tratam os arranjos institucionais como eventos naturais alheios a escolhas ou relações de poder, separando as organizações de seus contextos históricos, de suas composições e origens conflituosas;

2) Intenção desvinculada da performance, onde a busca por desenvolvimento de conhecimentos visa à superação das pessoas em relação aos mecanismos que as oprimem, rompendo com a lógica instrumental da maximização de resultados (pela eficiência, efetividade e eficácia) e com a suposta neutralidade científica, que não deixa espaço para questionamentos quanto a seus meios e, principalmente, seus propósitos. 
3) Intenção emancipatória, em que se enfatizam e promovem a autonomia e a responsabilidade dos indivíduos, entendendo-se por autonomia a capacidade dos sujeitos de desenvolverem julgamentos que não sejam impedidos ou subordinados a relações de poder e desigualdade ${ }^{6}$ e, por responsabilidade, a consciência de interdependência social, de compromisso coletivo.

Tomando por pressuposto que as teorias administrativas, em sua natureza, podem ser qualificadas como uma ciência social, vale adicionar aos critérios de criticidade já mencionados algumas notas, de Ramos (1957), sobre defeitos, ou tendências, presentes em boa parte dos estudos acadêmicos das ciências sociais no Brasil": o primeiro deles reside na simetria, encontrada na disposição desses estudiosos a adotar literalmente aquilo que se apresenta como mais avançado nos centros europeus e norte-americanos, e no sincretismo, fruto da tentativa desses autores de conciliar aqui doutrinas peculiares a outros países, portanto, de outras realidades; o segundo defeito consiste no dogmatismo da ampla assunção de argumentos de autoridade, em que as discussões e avaliações dos fatos esgotam-se na mera sobreposição de textos de autores prestigiados, o que leva ao dedutivismo, pois, ao considerar a validade absoluta das obras estrangeiras, estas passam a ser ponto de partida para a explicação dos eventos de contexto nacional; disto decorre a alienação das ciências sociais brasileiras, visto que estas não se originam de esforços inclinados a promover a autodeterminação da nossa sociedade; resulta dessas quatro características a inautenticidade, já que o estudioso brasileiro dessa área recebe e usa processos científicos pré-fabricados, não baseados em experiências cognitivas genuínas, porque não participa de sua gênese. O autor completa a ideia explanando a criticidade para estudos em ciências sociais em dois termos: serão críticos na medida em que forem autênticos e colaborem para a autoconsciência nacional, mas para tal tarefa devem ser precedidos pela autocrítica, a servir como instrumento para afastar equívocos e vícios de análise, o que também implica a disposição para o debate, no trabalho coletivo da construção dos pensamentos e o que os suceder.

Mais especificamente sobre a área da administração, Tragtenberg (2005) reforça essas posições críticas, relacionando-as à falsa representação das determinações sociais reais geradas pela ideologia administrativa das grandes corporações, a qual desconsidera os conflitos de classes e mesmo a existência de classes com interesses opostos, ou, quando o faz, trata a questão como problema a ser solucionado em prol da corporação, pois esta é tida num plano superior de relevância na sociedade em detrimento dos indivíduos que a suportam. Nessa ideologia também as discussões relativas a relações de poder não são representadas a partir de seus fatores de existência, mas suscitadas dentro de um pressuposto de que existem por 
uma "ordem natural dos fatos" a ser pensada em termos de otimização, e não de transfiguração, escamoteando o sentido das mudanças teóricas e práticas em novas maneiras que dizem respeito somente às formas e não ao conteúdo dessas relações de poder. Tratenberg (2005, p. 54) exemplifica o que isso significa, lembrando que "a linguagem tecnocrática ${ }^{8}$ emprega o termo inovação em lugar de mudança. Sucedem-se revoluções organizacionais que nada mudam, revoluções filosóficas que são revoluções filológicas". Disso decorre o equívoco envolto sob o nome racionalidade, visto que esse sistema carrega consigo o caráter de conservação de seus arranjos, de sua ordem.

Para a definição de outro conceito fundamental àquilo que se pretende neste artigo, o da ação administrativa, faz-se necessária a distinção de ao menos duas compreensões sobre a racionalidade, a exemplo de Ramos (1981, p. 23), quando escreve que "a razão é o conceito básico de qualquer ciência da sociedade e das organizações": na racionalidade funcional aprecia-se uma série sistemática de atos, independentemente do conteúdo que possam ter essas ações, para atingir um objetivo predeterminado; já a racionalidade substancial está ligada às ações intrinsecamente inteligentes, baseadas em conhecimentos lúcidos e autônomos das relações entre os fatos, que atestam a transcendência do ser humano, disserta Ramos (1983). O autor afirma que a razão da ação administrativa não é entendida como faculdade humana transcendental, mas restringe-se à eficácia e a operações produtivas que combinem recursos e meios de trabalho com vistas à concretização de objetivos contingentes, sendo que a inteligência da ação administrativa também requer outras referências sistemáticas, entre elas a racionalidade substancial.

Ainda que pareça evidente a importância da relação entre as racionalidades e as ações administrativas, Tragtenberg (1982) declara que o afastamento entre o pensamento e a ação revela uma das doenças que tipificam a delinquência acadêmica, que também pode ser compreendida como delinquência intelectual, já que a valorização de uma pessoa que se possa dizer culta passa pelas ideias que defende, pelo seu discurso, pelo seu comportamento, por sua existência, os quais, por si mesmos, já constituem atos políticos, formas de ação indistinguíveis da razão. O autor refere-se a essa desvinculação como delinquência, mais precisamente nos meios educativos, pelo engessamento burocrático causado pela inversão de valores pedagógicos em que as técnicas (meios) se tornam fins e as finalidades formativas são pormenorizadas, ou até abandonadas. A busca por conhecimento e sua propagação, sua incorporação pelos indivíduos, dá lugar à produção burocraticamente regimentada e parametrizada desse saber. Dadas essas circunstâncias, a maneira sugerida pelo autor para que as academias - o que pode ser compreendido como válido para todas as instituições de ensino - voltem a ter sentido em suas existências está na autogestão pedagógica, a qual não transformaria questões políticas 
em problemas técnicos, nem trocaria vontades e decisões públicas por decisões de gabinete, sendo, possivelmente, capaz de romper com a inversão de valores e estruturas antes mencionadas. Ressalte-se que a proposição não é defendida como solução, mas possibilidade, considerando o que argumenta Lima (2001, p. 112):

\begin{abstract}
Não basta alterar as regras formais para mudar as realidades escolares, e estas mudam, com frequência, mesmo quando as primeiras se mantêm inalteradas. Ou seja, não são apenas os modelos decretados que influenciam as práticas de gestão; estas práticas são influenciadas por múltiplos factores, objectivos, interesses, circunstâncias etc., que, por sua vez, não deixam de influenciar o entendimento e até a produção dos modelos decretados. E, assim, as diversas realidades escolares não se transformam automaticamente por simples mudança dos modelos decretados, como também a mera manutenção destes não assegurará necessariamente a cristalização de tais realidades.
\end{abstract}

Ao mesmo tempo em que a sugerida autogestão no ensino não deve ser vista como solução definitiva dos problemas da gestão escolar, tendo em conta os trabalhos de Maurício Tragtenberg examinados, também não é correto associá-la à acepção de Lima (2001) de doutrina gestionária, ou modelo organizacional normativista e pragmático, cuja função é reproduzir, regulamentar e manter as estruturas organizacionais formais; mas pelo contrário, partindo de uma interpretação compartilhada também por Paes de Paula (2008), a autogestão defendida por Tragtenberg procura valorizar bases organizacionais democráticas, com relações horizontalizadas e cooperativistas, participação direta ${ }^{9}$ da sociedade civil e dos diversos atores da organização não somente nas decisões, como nos processos de constituição e funcionamento da organização. E se fica a impressão de que a autogestão é utópica, maneira pela qual a ideia é frequentemente rotulada, Motta (2001, p. 66) indica a incoerência dessa suposição atentando para o fato de que, todavia, "é bem menos comum a identificação do ideal do progresso técnico como via de construção de uma sociedade de bem-estar como utopia".

\title{
Considerações finais
}

Conclui-se que há grande proximidade entre concepções da gestão escolar democrática e dos Estudos Organizacionais Críticos apresentados, a qual é observável tanto nas similaridades dos principais autores citados do quadro teórico de referência - pelos caminhos argumentativos de conceitos e valores que percorrem, em que, pautados por uma racionalidade não funcional, demonstram notável profundidade e criticidade nas suas fundamentações teóricas juntamente com ampla ponderação do caráter e dos aspectos de outras teorias -, quanto nas semelhantes perspectivas emancipatórias que defendem para os sujeitos individuais e coletivos. Dessas constatações podem ser feitas duas recomendações para futuras pesquisas: 
- Buscar a ampliação do espaço de diálogo entre teorias educacionais e teorias organizacionais, partindo dessas correntes teóricas, convergentes sob vários pontos de vista, tanto da área da administração quanto da educação.

- Apontar a autogestão como possibilidade a ser considerada para os ideais democráticos de gestão escolar.

\section{Notas}

1. Entretanto, Paro (2001a, p. 109) recorda que é preciso desmistificar a falsa ideia de que já temos no Brasil escola para todos, ou quase todos, pois a quantidade "não pode existir no vazio sem referir-se a alguma qualidade", dada a situação precária de tantas escolas brasileiras que não satisfazem sequer as mínimas condições de convivência humana e os mais elementares critérios didático-pedagógicos.

2. Sobre o provimento de cargo de diretores, recomenda-se também Dourado (2006).

3. Conforme o conceito marxista de alienação, que pode ser encontrado em Marx (2002).

4. As reflexões e exemplos históricos acerca do participacionismo e da autogestão neste artigo referem-se aos livros de Prestes Motta et al. (1987) e Tragtenberg (2005).

5. Paes de Paula (apud GONZÁLEZ-REY, 2008, p. 32-33) explica a autoconsciência por: “[...] um sujeito que, embora esteja sendo constituído por configurações subjetivas das quais não pode se conscientizar, está ao mesmo tempo produzindo de forma consciente um conjunto de projetos, reflexões e representações que são fontes de significados e sentidos que influenciarão o próprio desenvolvimento de sua subjetividade", e completa essa definição salientando que, "assim, emerge um sujeito reflexivo, capaz de questionar o mundo em que vive, noção que desafia a ideia de morte do sujeito e mesmo a ausência dessa categoria [...]".

6. A desigualdade traz consigo uma valoração de inferior ou superior, de positivo ou negativo, estabelecendo uma relação de poder, de hegemonia entre as partes, segundo Benevides (s.d., p. 11).

7. Considerando que essas observações não são definitivas, de acordo com Ramos (1957, p. 26), e nem se aplicam a todas as ciências sociais, elas ainda podem ser facilmente verificadas, nos dias atuais, em alguns compêndios nacionais (de larga utilização) sobre teorias administrativas, como Chiavenato (2009) e Maximiano (2004).

8. Nesse contexto a tecnocracia e a burocracia podem ser mais bem compreendidas pelas obras de Prestes Motta (2001) e Tragtenberg (1992).

9. Diferentemente da cogestão que é, na verdade, conforme Tragtenberg (2005), uma pseudoparticipação, já que escamoteia uma democratização parcial, portanto uma falsa democratização.

\section{Referências}

ARROYO, M.G. Políticas educacionais e desigualdades: à procura de novos significados. Educação \& Sociedade, Campinas, v. 31, n. 113, p. 1381-1416, dez. 2010.

BENEVIDES, M.V.M. Cidadania e direitos humanos. São Paulo: IEA/USP, [s.d.]. Disponível em: $<\mathrm{http}: / / \mathrm{www}$.iea.usp.br/textos/benevidescidadaniaedireitoshumanos.pdf $>$. Acesso em: jun. 2010. 
BRASIL. Constituição (1988). Constituição da República Federativa do Brasil. Brasília, DF: Senado Federal, 1988.

BRASIL. Lei n. 9.394, de 20 de dezembro de 1996. Estabelece as diretrizes e bases da educação nacional. Diário Oficial da União, Brasília, DF, 23 dez. 1996.

CALDAS, M. et. al. (Ed.). Handbook de estudos organizacionais. São Paulo: Atlas, 2001.

CHIAVENATO, I. Administração: teoria, processo e prática. São Paulo: Elsevier, 2009.

DAVEL, E.; ALCADIPANI, R. Estudos críticos em administração: a produção científica brasileira nos anos 1990. Revista de Administração de Empresas, São Paulo, v. 43, n. 4, p. 72-85, out./dez. 2003.

DEMO, P. Introdução à metodologia da ciência. São Paulo: Atlas, 2008.

DOURADO, L.F. A escolha de dirigentes escolares: políticas e gestão da educação no Brasil. In: FERREIRA, N.S.C. (Org.). Gestão democrática da educação: atuais tendências, novos desafios. 5. ed. São Paulo: Cortez, 2006. p. 77-95.

DOURADO, L.F.; OLIVEIRA, J.F.; SANTOS, C.A. A qualidade da educação: conceitos e definições. Série Documental: Textos para Discussão, Brasília, DF, v. 24, n. 22, p. 5-34, 2007. Disponível em: <http://www.redecaes.com.br/luiz.html>. Acesso em: 13 jul. 2010.

FARIA, J.H. Consciência crítica com ciência idealista: paradoxos da redução sociológica na fenomenologia de Guerreiro Ramos. Cadernos Ebape.BR, Rio de Janeiro, v. 7, n. 3, p. 420-446, set. 2009.

GARCIA, T.O.G. A organização do trabalho na escola e a participação dos educandos. Educação: Teoria e Prática, Rio Claro, v. 14, n. 26, p. 67-93, jan./jun. 2006.

GONZÁLEZ-REY, F.L. Sujeito e subjetividade: uma aproximação histórico-cultural. São Paulo: Pioneira; Thomson Learning, 2003.

KUENZER, A. A pedagogia da fábrica: as relações de produção e a educação do trabalhador. São Paulo: Cortez, 1985.

LIMA, L.C. A escola como organização educativa: uma abordagem sociológica. São Paulo: Cortez, 2001.

MARX, K. Manuscritos econômico-filosóficos. São Paulo: Martin Claret, 2002.

MAXIMINIANO, A.C.A. Teoria geral da Administração. 4. ed. São Paulo: Atlas, 2004.

MENDONÇA, E.F. A regra e o jogo: democracia e patrimonialismo na educação brasileira. Campinas: FE/Unicamp, 2000. 
MOTTA, F.C.P. et al. Participação e participações: ensaios sobre autogestão. São Paulo: Babel Cultural, 1987.

MOTTA, F.C.P. Teoria das organizações: evolução e crítica. 2. ed. São Paulo: Thomson Learning, 2001.

OLIVEIRA, M.R.S. Racionalidade e organizações: o fenômeno das organizações substantivas. 1996. 633p. Tese (Doutorado) - Escola de Administração de Empresas, Fundação Getúlio Vargas, São Paulo.

PAES DE PAULA, A.P. Por uma nova gestão pública: limites e potencialidades da experiência contemporânea. Rio de Janeiro: FGV, 2005.

PAES DE PAULA, A.P. Teoria crítica nas organizações. São Paulo: Thomson Learning, 2008.

PAES DE PAULA, A.P. et al. A tradição e a autonomia dos estudos organizacionais críticos no Brasil. Revista de Administração de Empresas, São Paulo, v. 50, n. 1, p. 10-23, jan./mar. 2010.

PARO, V.H. Gestão democrática da escola pública. 3. ed. São Paulo: Ática, 2001a.

PARO, V.H. Administração escolar: introdução crítica. 10. ed. São Paulo: Cortez, 2001b.

PARO, V.H. Gestão escolar, democracia e qualidade do ensino. São Paulo: Ática, 2007.

PINTO, J.M.R. Administração e liberdade: um estudo do Conselho de Escola à luz da teoria da ação comunicativa de Jürgen Habermas. Rio de Janeiro: Tempo Brasileiro, 1996.

RAMOS, A.G. Introdução crítica à sociologia brasileira. Rio de Janeiro: Andes, 1957.

RAMOS, A.G. A nova ciência das organizações: uma reconceituação da riqueza das nações. Rio de Janeiro: FGV, 1981.

RAMOS, A.G. Administração e contexto brasileiro: esboço de uma teoria geral da administração. 2. ed. Rio de Janeiro: FGV, 1983.

SAVIANI, D. Escola e democracia. Edição comemorativa. Campinas: Autores Associados, 2008.

TRAGTENBERG, M. Sobre educação, politica e sindicalismo. São Paulo: Cortez, 1982.

TRAGTENBERG, M. Burocracia e ideologia. 2. ed. São Paulo: Ática, 1992.

TRAGTENBERG, M. Administração, poder e ideologia. 3. ed. São Paulo: Unesp, 2005.

Recebido em 26 de agosto de 2011.

Aprovado em 22 de junho de 2012. 